\title{
Intramammary Emulsion Dosage Form
}

National Cancer Institute

\section{Source}

National Cancer Institute. Intramammary Emulsion Dosage Form. NCI Thesaurus. Code C149604.

Liquid sterile preparation for veterinary use consisting of an emulsion intended for intramammary use. Intramammary emulsions are presented in intramammary syringes for use on one occasion only to introduce the emulsion into a single teat canal. 